\title{
Promoting Independence in Dementia (PRIDE): A Feasibility Randomized Controlled Trial
}

This article was published in the following Dove Press journal:

Clinical Interventions in Aging

\author{
Emese Csipke (D) \\ Aisha Shafayat $\mathbb{D}^{2}$ \\ Kirsty Sprange $\mathbb{D}^{2}$ \\ Lucy Bradshaw ${ }^{2}$ \\ Alan A Montgomery ${ }^{2}$ \\ Reuben Ogollah $\mathbb{D}^{2}$ \\ Esme Moniz-Cook $\mathbb{D D}^{3}$ \\ Martin Orrell (iD) ${ }^{4}$ \\ 'Division of Psychiatry, University \\ College London, London, UK; \\ ${ }^{2}$ Nottingham Clinical Trials Unit, \\ University of Nottingham, Nottingham, \\ UK; ${ }^{3}$ Faculty of Health Sciences \\ University of Hull, Hull, UK; ${ }^{4}$ Institute of \\ Mental Health, University of Nottingham, \\ Nottingham, UK
}

Background: There is a need for interventions to foster and maintain independence for people with dementia to support community living, improve morale, and reduce stigma. We investigated a social intervention to promote living well and enhance independence for people with mild dementia.

Methods: In this two arm parallel group, feasibility RCT at six sites in England, participants were randomized (1:1) to the PRIDE intervention (encompassing social, physical, and cognitive domains supported by a facilitator over three sessions) compared to usual care only. The main objective was to determine the feasibility of a main trial with respect to measures of recruitment, retention, and adherence to the intervention.

Results: During a 7-month period, 402 people were invited to the trial, 148 were screened $(37 \%, 95 \%$ confidence interval $(\mathrm{CI})=32-42 \%), 137$ were eligible at pre-consent, 94 consented to the trial ( $69 \%$ of those eligible, $95 \% \mathrm{CI}=60-76 \%$ ), and 92 were randomized (46 to each group). Of those allocated to the intervention, 42 (91\%) received at least one of three intervention sessions. Outcome assessment follow-up visits were completed for 73 participants at 6 months $(79 \%, 95 \% \mathrm{CI}=70-87 \%)$, and this was similar for both groups.

Conclusion: A large multi-center trial of the PRIDE intervention in community-dwelling people with mild dementia is feasible using systematic recruitment strategies. The intervention was successfully delivered and well received by participants. Findings from this study will be used to refine the design and processes for a definitive RCT.

Trial Registration: ISRCTN, ISRCTN11288961, registered on 23 October 2018.

Keywords: dementia, feasibility trial, randomized controlled trial, psychosocial intervention

\section{Background}

People with dementia lose independence for many reasons, such as neurological deterioration, reduced living skills, or negative social consequences, such as stigma, social exclusion, and disempowerment. Receiving specialist support soon after diagnosis may facilitate independence in early stage dementia. Family and friends may also inadvertently contribute to a reduced sense of autonomy in people with dementia by a lowered set of expectations, and well intentioned "taking over" of decision-making and responsibilities in order to support their relative. ${ }^{1}$ Fundamental concerns for people with dementia include loss of power in social relationships, the need to maintain active roles outside their immediate social networks, and a dearth of information on diagnosis, prognosis, and post-diagnostic support services. Both the UK government and the EU Joint Program for Neurodegenerative Disease Research have underscored the need for high quality psychosocial interventions, to support the growing post-diagnostic needs of people with dementia. ${ }^{2}$
Correspondence: Emese Csipke

Division of Psychiatry, University College London, 6th Floor, Maple House, 149

Tottenham Court Road, London, WIT

7NF, UK

Email e.csipke@ucl.ac.uk
Clinical Interventions in Aging 2021:16 363-378 
The Promoting Independence in Dementia (PRIDE) program was developed as a post-diagnostic social intervention $^{3,4}$ to support independence and quality-oflife for people with early stage dementia, so that they could live well and as independently as possible in the community. The PRIDE intervention includes the principles of self-management as applied to the treatment of chronic conditions, ${ }^{5}$ including teaching the individual how to manage their condition and identify solutions specific to their needs. ${ }^{6}$ Strategies can include decisionmaking, identifying and using available resources, problem-solving, and being an active participant in choices about care, in partnership with healthcare professionals. ${ }^{7,8}$ PRIDE promotes social inclusion, harnesses the support of the person's social network, and facilitates engagement in stimulating cognitive, physical, and social activities. The intervention is aimed at those with mild dementia who are likely to have minor difficulties with daily living activities. It was manualized using the conceptual frameworks and associated mechanisms of action that were identified within the research program. ${ }^{9}$ It allows individualized tailoring according to the person's needs and circumstances using co-production approaches to develop the intervention.

Previous groundwork involved a mixed-methods nonrandomized, pre-post feasibility study, conducted at four sites. ${ }^{10}$ This found that the intervention was acceptable where $73 \%$ completed all three sessions. However, recruitment and delivery within the voluntary sector was not effective. The present feasibility study was delivered in an alternative setting, utilizing NHS services for delivery of the intervention. We also wished to examine whether the variable recruitment rates we noted previously could be improved using site-specific requirements. This information about availability of intervention facilitators and site-based requirements for recruitment is of key importance for determining the feasibility of a future large-scale definitive RCT.

The aim of this study was to investigate the feasibility of the PRIDE intervention, within a randomized controlled design to inform a future large scale definitive RCT of the clinical and cost effectiveness. This study examined in detail screening, recruitment, and follow-up rates, and the potential of clinical outcome measures within a RCT design, as we were interested in completion rates of follow-up data, particularly for those not allocated to the intervention group. The embedded qualitative study, fidelity assessment, and data to inform the cost-effectiveness analysis will be reported elsewhere.

\section{Methods/Design}

This PRIDE randomized feasibility study was designed as a two arm parallel group multi-center study with participants individually allocated on a 1:1 ratio to usual care or usual care plus the PRIDE intervention. It also included an embedded qualitative process evaluation (see protocol ${ }^{11}$ for design and methods).

\section{Participants}

Recruitment took place in six NHS sites across England, with participants identified via the NHS, Joint Dementia Research (JDR; an online research register) and selfreferral. Participants were eligible if they were within the selected site-catchment area; aged over 18 years; met the Diagnostic and Statistical Manual of Mental DisordersFourth Edition criteria for dementia of any type; were able to provide informed consent and engage in the intervention in the opinion of the investigator (or designee); were able to $\mathrm{read} /$ communicate in English; and were not living in institutional care. In addition, the participant must have had mild dementia, defined as a score of 0.5 or 1 on the Clinical Dementia Rating (CDR) Scale, which was assessed at the baseline visit after consent. Participants were able to take part with or without a supportive other (eg, carer). If taking part, the supporter was eligible if they were aged 18 or over; able to engage with and participate in the intervention; and able to provide informed consent and read and communicate verbally in English. After identification, a member of the site research team contacted the potential participant to confirm initial eligibility and to arrange a baseline assessment. At the home visit, the researcher explained the study, obtained written informed consent, and collected baseline data including the CDR scale ${ }^{12}$ to confirm eligibility.

Follow-up visits were conducted at 3 and 6 months postrandomization in the participant's home by a site research team member blind to group allocation. Questionnaires for supporters were either completed at the visit if the supporter was present or left with a prepaid envelope for the supporter to return to the coordinating center.

\section{Facilitation}

\section{Training}

Training by the research team involved a 1-day session developed through co-production and consultation with voluntary sector dementia advisors and NHS memory 
clinic nurses. The theories underlying the intervention were provided, followed by group work, role play, and discussion. Facilitators all had a background of working with dementia. Trainers were available throughout the study for continued support.

\section{Usual Care and Intervention}

All participants received the services usually available to people with dementia at the participating sites. In addition, participants allocated to the intervention arm received the PRIDE intervention. ${ }^{4}$ The three-session intervention is delivered by trained intervention facilitators. Each session lasts between 1-2 hours conducted in a venue selected by the participant, usually their own home. Working together, the intervention provider and participant develop a personalized profile for the person with dementia. This is followed by a collaborative approach to planning for doing activities that are important to the person with dementia. These plans are reviewed in subsequent sessions and modified if necessary. A paper manual guides the intervention and includes signposting to information and resources, and an electronic version was also available allowing participants to choose either or both if they wished. ${ }^{4}$

\section{Outcomes}

\section{Feasibility Outcomes}

The primary outcome of this study was the feasibility set within an RCT design to explore further what is required for delivery of large scale definitive RCT of the PRIDE intervention. The objectives and outcomes are shown in Table 1.

\section{Clinical Outcomes}

Nine clinical outcomes measures for participants, described in Table 2 to collect data on domains recommended to evaluate psychosocial interventions in dementia, ${ }^{13,14}$ were collected at the baseline, 3 , and 6 months. These outcomes covered Activities of Daily Living, ${ }^{15}$ Quality-of-Life (DEMQoL ${ }^{16}$ ), EQ5D-5L, ${ }^{17}$, Mood (GDS-15 $\left.{ }^{18}\right)$, Cognition $\left(\mathrm{SMMSE}^{19}\right)$, Wellbeing $\left(\mathrm{CASP}^{20}\right)$, Quality of relationships (IPAQ- $\mathrm{O}^{21}$ ), and Positive emotions $\left(\mathrm{PPOM}^{22}\right)$. In addition, participants were asked to provide a rating of their perceived change in wellbeing and independence compared to the start of the study (global change) to be used to explore the responsiveness to change of the clinical outcome measures. Supporters were similarly asked to provide a rating of their perceived change for the person with dementia in wellbeing and independence. Questionnaires were read out to participants to ensure consistency and promote inclusiveness for those who found reading text difficult.

\section{Sample Size}

As this was a feasibility study, a formal sample size calculation for between group comparisons of a primary outcome was not appropriate. A target sample size of 7580 participants was set over the recruitment period to establish recruitment capability of the range of participating services. Seventy-five participants at randomization allowed estimation of recruitment with a margin of error (half-width of 95\% confidence interval) of around 8 percentage points, and retention of 12 percentage points.

\section{Randomization}

Participants were allocated at the individual level to intervention or control on a $1: 1$ ratio using a minimization algorithm with a probabilistic element, created by the Nottingham Clinical Trials Unit (NCTU). The minimization variables were site, gender, age $(<80$ or $\geq 80)$ and medication for dementia (any vs none). The investigator or "authorized designee" randomized participants, following completion of the baseline assessments, using a remote, internet-based randomization system. Following randomization, participants were notified of their treatment allocation by an unblinded member of the research team. Researchers remained blind to allocation.

\section{Statistical Analyses}

Data analysis were primarily descriptive. All analyses were documented in a Statistical Analysis Plan which was finalized prior to database lock. Feasibility outcomes were estimated using descriptive statistics (with 95\% confidence intervals - CI - if relevant) and included recruitment rates, follow-up rates in both arms of the trial, missing data, and intervention adherence. Demographic and clinical characteristics at baseline were summarized in the two allocated groups. Clinical outcomes were summarized descriptively for participants with outcome data regardless of adherence with the allocated intervention.

Three clinical outcomes, the Lawton Instrumental Activities of Daily Living (IADL) scale, quality-of-life using the DEMQoL and wellbeing using Control, Autonomy, Self-realization, and Pleasure scale (CASP, scored from both 19-item and 12-item version), were chosen as candidate primary outcomes to evaluate their 
Table I Feasibility Objectives and Outcomes

\begin{tabular}{|c|c|}
\hline Feasibility Objectives & Feasibility Outcomes \\
\hline I. Determine the feasibility of recruitment to a large-scale RCT & $\begin{array}{l}\text { (a) Aggregate data on potential participants within NHS services } \\
\text { (b) Number of patients assessed for eligibility/consented/randomized } \\
\text { (c) Number and proportion of potential participants identified through } \\
\text { NHS services, Join Dementia Research, and by self-referral who are } \\
\text { eligible } \\
\text { (d) Reasons for non-inclusion/non-eligibility } \\
\text { (e) Monthly recruitment rate per site } \\
\text { (f) Barriers and facilitators to recruitment (Interviews/focus groups) }\end{array}$ \\
\hline 2. Refine the eligibility criteria for a future definitive RCT & $\begin{array}{l}\text { (a) Number of screening failures for eligibility, post-consent } \\
\text { (b) Participant and facilitator report (Interviews/focus groups) }\end{array}$ \\
\hline 3. Determine the acceptability to patients/clinicians of randomization & $\begin{array}{l}\text { (a) Proportion of eligible patients that consent to randomization } \\
\text { (b) Reasons for non-consent } \\
\text { (c) Participant and facilitator report (Interviews/focus groups) }\end{array}$ \\
\hline $\begin{array}{l}\text { 4. Determine the relevance and acceptability to patients/clinicians of } \\
\text { the trial intervention }\end{array}$ & $\begin{array}{l}\text { (a) Premature discontinuation or non-attendance of treatment and } \\
\text { reasons } \\
\text { (b) Feedback from participants and site staff delivering the intervention } \\
\text { (c) Participant and facilitator report (Interviews/focus groups) }\end{array}$ \\
\hline $\begin{array}{l}\text { 5. Determine the acceptability to patients/clinicians of the trial } \\
\text { procedures }\end{array}$ & $\begin{array}{l}\text { (a) Proportion of approached NHS sites that agree to participate in the } \\
\text { trial and reasons for non-participation } \\
\text { (b) Proportion of eligible patients that consent to randomization } \\
\text { (c) Reasons for non-consent } \\
\text { (d) Withdrawals and losses to follow-up and reasons } \\
\text { (e) Feedback from participants and staff (Interviews/focus groups) }\end{array}$ \\
\hline 6. Assess the ability of NHS sites to deliver the intervention & $\begin{array}{l}\text { (a) Measures of the feasibility of delivering the PRIDE intervention within } \\
\text { NHS settings: number/grade/experience of staff within the service, } \\
\text { staff turnover, and time to treatment initiation } \\
\text { (b) Measures of the recruitment and retention of PRIDE facilitators dur- } \\
\text { ing the study treatment period } \\
\text { (c) Barriers to treatment delivery per protocol (Interviews/focus groups) }\end{array}$ \\
\hline $\begin{array}{l}\text { 7. Assess training and support needs for NHS staff delivering the } \\
\text { intervention }\end{array}$ & $\begin{array}{l}\text { (a) Feedback on training delivered (Interviews/focus groups) } \\
\text { (b) Support offered/accepted (eg, log of calls and emails to central sup- } \\
\text { port lines) }\end{array}$ \\
\hline 8. Evaluate treatment fidelity when delivered through NHS services & $\begin{array}{l}\text { (a) Measures of treatment fidelity including: adherence to intervention } \\
\text { manual and uptake of activities } \\
\text { (b) Feedback from participants and staff (Interviews/focus groups) }\end{array}$ \\
\hline $\begin{array}{l}\text { 9. Determine the services and interventions provided as usual care } \\
\text { and evaluate methods for measuring this }\end{array}$ & $\begin{array}{l}\text { (a) Post-diagnostic care pathway } \\
\text { (b) Services available } \\
\text { (c) Uptake of services }\end{array}$ \\
\hline 10. Assess follow-up and outcome completion rates & $\begin{array}{l}\text { (a) Response rate to follow-up assessment } \\
\text { (b) Questionnaire completion rates } \\
\text { (c) Amount of missing questionnaire data at item and scale levels }\end{array}$ \\
\hline $\begin{array}{l}\text { II. Determine the relevance and acceptability of a range of clinical } \\
\text { outcome measures and selection of the primary outcome for the } \\
\text { main trial }\end{array}$ & $\begin{array}{l}\text { (a) Completion rates and reasons for non-completion/missing data } \\
\text { (b) Estimates of clinically important differences, variance, and sensitivity } \\
\text { to change for the clinical outcome measures } \\
\text { (c) Direct questions to participants regarding relevance of measures }\end{array}$ \\
\hline
\end{tabular}

(Continued) 
Table I (Continued).

\begin{tabular}{|c|l|}
\hline Feasibility Objectives & Feasibility Outcomes \\
\hline $\begin{array}{c}\text { I2. Evaluate the utility and acceptability of resource use question- } \\
\text { naires for use in an economic evaluation alongside a future RCT }\end{array}$ & (a) Completion rate and reasons for non-completion/missing data \\
\hline I3. Comparative micro-costing of PRIDE intervention and usual care & $\begin{array}{l}\text { (a) Staff time and resources for delivery of PRIDE intervention } \\
\text { (b) Other service use }\end{array}$ \\
\hline 14. Estimate the sample size required for a definitive study & $\begin{array}{l}\text { (a) Primary outcome selection } \\
\text { (b) Variability in the outcome } \\
\text { (c) Withdrawals and losses to follow-up }\end{array}$ \\
\hline I5. Determine the resources required for a full trial & $\begin{array}{l}\text { (a) Sample size, recruitment rate (number of sites/recruitment period), } \\
\text { staffing and resources (for recruitment, treatment and follow-up) }\end{array}$ \\
\hline
\end{tabular}

responsiveness and minimal important change (MIC), ${ }^{25}$ against the global change questions at 6 months (see Supplementary Methodology 1).

It was not an objective of this feasibility study to obtain definitive estimates of the intervention effect on clinical outcomes as it was not powered to do so. However, differences in means between groups (with CIs) for the candidate primary outcomes described above at 6 months were calculated using linear mixed models, adjusted for the minimization variables with a random effect for the recruiting site, to show the possible range of treatment effects. Adjusted differences in means are presented with $95 \%, 85 \%$, and $75 \%$ CIs in forest plots to explore the strength of the preliminary evidence. ${ }^{26}$

\section{Results}

\section{Sites and Recruitment}

Fifty-three sites were approached through a national Memory Services register, of which 29 (55\%) expressed an interest and $19(36 \%)$ returned the study eligibility questionnaire. Of these, $12(63 \%)$ met the eligibility criteria and six were selected. Sites were geographically spread and covered urban and rural areas, a wide socioeconomic distribution, and varied in terms of the size of the populations they served. Overall, 46 research staff were involved in the study, ranging from three to 12 per site. Nineteen staff were trained to be facilitators, and comprised of nurses, occupational therapists, clinical researchers, and assistant psychologists.

The sites opened to recruitment between November 2018 and February 2019. Figure 1 summarizes the participant flow into the trial. Of the 402 people invited, 148 were screened $(37 \%, 95 \% \quad \mathrm{CI}=32-42 \%)$, with a mean age of 77 years $(\mathrm{SD}=8.1)$ and half were female. Of those screened, 137 (93\%) were eligible preconsent, 94 consented to the trial $(69 \%$ of those eligible, $95 \% \mathrm{CI}=60-76 \%)$, and 92 were randomized $(67 \%, 95 \%$ $\mathrm{CI}=59-75 \%$ ), 46 to each arm. Following screening, one site contributed to most of the 54 "non-consenting" participants and, of those, the majority could not be contacted again after the initial approach $(n=23)$ or declined to participate $(n=10)$. The number of participants randomized per site ranged from 11-22, with a mean of 2.6 participants randomized per month.

Randomized participants had a mean age of 78 $(\mathrm{SD}=8.0)$, half were female, most were of white ethnicity (93\%), and approximately two thirds had Alzheimer's type dementia (Table 3). Baseline characteristics were in general well balanced across the two groups, although slightly more participants in the PRIDE intervention group were married (or had a partner) and lived with others compared to the usual care group (Table 3). Around two thirds of participants chose to take part with a supporter and the majority of supporters were a spouse or partner (Table 3 ).

Of those allocated to the intervention, 42 (91\%) received at least one intervention session, with 42 (91\%) attending the first session, 34 (74\%) the second, and 33 $(72 \%)$ the third session. The main reason for nonattendance at sessions was withdrawal from the study, occurring at session $2(n=5)$ and session $3(n=6)$. The paper manual was used for all participants, apart from one participant who used both the paper and electronic versions.

Outcome assessment visits were completed for 78 participants $(85 \%, 95 \% \mathrm{CI}=76-91 \%)$ at 3 months and 73 $(79 \%, 95 \% \mathrm{CI}=70-87 \%)$ at 6 months and completion 
Table 2 Summary of the Clinical Outcome Measures

\begin{tabular}{|c|c|c|}
\hline Outcome Measures & Scale, Description, and Source & Derivation of Scores ${ }^{A}$ \\
\hline \multicolumn{3}{|l|}{ Participants } \\
\hline Activities of Daily Living & $\begin{array}{l}\text { - Measured using the Lawton Instrumental Activities of Daily } \\
\text { Living (IADL) Scale }{ }^{15} \\
\text { - Performance is measured across eight domains }\end{array}$ & $\begin{array}{l}\text { - Each domain has between three and five response options } \\
\text { describing ability. These are scored as } 0 \text { (less able) or I (more } \\
\text { able) } \\
\text { - Domain scores summed to produce summary score from } 0 \text { (low } \\
\text { function) to } 8 \text { (high function) }\end{array}$ \\
\hline $\begin{array}{l}\text { Health-related quality- } \\
\text { of-life }\end{array}$ & $\begin{array}{l}\text { - Measured using EuroQoL Quality-of-Life Questionnaire - } 5 \\
\text { Domains, } 5 \text { Levels }{ }^{17} \\
\text { - Consists of two parts: a descriptive system and a visual analog } \\
\text { scale (VAS) asking about health on that day } \\
\text { - The } 5 \text { level descriptive system used as part of the health } \\
\text { economic analysis and VAS summarized in the quantitative } \\
\text { analysis of the clinical outcomes }\end{array}$ & $\begin{array}{l}\text { - VAS scores range from } 0 \text { (worst health can imagine) to } 100 \text { (best } \\
\text { health can imagine) }\end{array}$ \\
\hline Quality-of-life & $\begin{array}{l}\text { - Measured using DEMQoL }{ }^{16} \\
\text { - Assesses five domains of quality-of-life including health and } \\
\text { well-being, cognitive functioning, social relationships and self- } \\
\text { concept }\end{array}$ & $\begin{array}{l}\text { - Scale consists of } 28 \text { items about the last week with four response } \\
\text { options (a lot, quite a bit, a little, and not at all) } \\
\text { - Items are scored as I=a lot, } 2=\text { quite a bit, } 3=\mathrm{a} \text { little, and } 4=\text { not } \\
\text { at all, apart from five positive questions, which are scored in } \\
\text { reverse } \\
\text { - Items are summed to produce a total score ranging from } 28-112 \text {, } \\
\text { higher scores indicating better quality-of-life } \\
\text { - Missing items are imputed with person-specific mean of com- } \\
\text { pleted items provided at least } 50 \% \text { of items are complete (ie, } 14 \\
\text { items) }\end{array}$ \\
\hline Mood & $\begin{array}{l}\text { - Measured using the Geriatric Depression Scale (GDS) - short } \\
\text { form }^{18}\end{array}$ & $\begin{array}{l}\text { - I5-items about the last week with responses of yes or no } \\
\text { - Items scored as I when response indicates depression and } 0 \\
\text { otherwise ( } 10 \text { items indicate the presence of depression when } \\
\text { answered positively, and five items when answered negatively) } \\
\text { - Item scores summed to produce a total score ranging from 0-15, } \\
\text { with higher scores indicating more severe depression }\end{array}$ \\
\hline Cognition & $\begin{array}{l}\text { - Measured using the Standardized Mini Mental State Exam } \\
(\text { S-MMSE) })^{19}\end{array}$ & $\begin{array}{l}\text { - Brief assessment of cognition testing orientation (time and } \\
\text { place), repetition, verbal recall, attention and calculation, lan- } \\
\text { guage and visual construction } \\
\text { - The total test score is the sum of the correct responses ranging from } \\
\text { 0-30, with a lower score indicating more cognitive impairment } \\
\text { - An adjusted score can be calculated for people who are physi- } \\
\text { cally unable to do some of the tasks on the MMSE (IHPA } \\
\text { Australia) }\end{array}$ \\
\hline Wellbeing & $\begin{array}{l}\text { - Control, Autonomy, Self-realization, and Pleasure (CASP) } \\
\text { questionnaire }{ }^{20} \\
\text { - Assesses quality-of-life in older people across four domains; } \\
\text { control, autonomy, pleasure, and self-realization }\end{array}$ & $\begin{array}{l}\text { - } 19 \text { items with four response options (often, sometimes, not } \\
\text { often, and never) } \\
\text { - Items scored on a 4-point Likert scale as shown on the CASP } \\
\text { website (https://casp 19.com/casp-scoring-and-properties/). } \\
\text { - Items scores summed to produce a total score ranging from 0- } \\
57 \text {, with higher scores indicating better quality-of-life. } \\
\text { - The } 12 \text { item version of the CASP also used as this has been found to } \\
\text { have a better factor structure for people with dementia than the } 19 \\
\text { item. }{ }^{19} \text { In the } 12 \text { item version, items } 3 \text { (control subscale), items } 6 \text { and } \\
8 \text { (autonomy subscale), items } 13 \text { and } 14 \text { (pleasure subscale), and } \\
\text { items } 16 \text { and } 17 \text { (self-realization subscale) are not used }\end{array}$ \\
\hline
\end{tabular}

(Continued) 
Table 2 (Continued).

\begin{tabular}{|c|c|c|}
\hline Outcome Measures & Scale, Description, and Source & Derivation of Scores ${ }^{\mathbf{A}}$ \\
\hline Quality of relationships & $\begin{array}{l}\text { - Measured using Impact on Participation and Autonomy } \\
\text { Questionnaire for older people (IPAQ-O) social relations } \\
\text { subscale }^{21}\end{array}$ & $\begin{array}{l}\text { - Social relations subscale has five items with five response items } \\
\text { - The response options on the PRIDE CRF were very good, good } \\
\text { fair, poor, and very poor from the original IPAQ }{ }^{23} \text { rather than } \\
\text { amended response options for the IPAQ-O (totally agree, partly } \\
\text { agree, neither agree nor disagree, disagree, and totally disagree) } \\
\text { - The response options were scored as on the original IPAQ: very } \\
\text { good=I, good=2, fair=3, poor }=4 \text {, and very poor }=5 \\
\text { - Item scores summed to produce a total score ranging from 5- } \\
\text { 25, with higher score indicating more restriction in participation }\end{array}$ \\
\hline Positive emotions & $\begin{array}{l}\text { - Measured using the Positive Psychology Outcome Measure } \\
\text { (PPOM) })^{22} \\
\text { - Two subscales: hope and resilience }\end{array}$ & $\begin{array}{l}\text { - I6-item scale measuring aspects of positive psychology with an } \\
\text { eight item hope subscale and an eight item resilience subscale } \\
\text { - Each item is rated on a } 5 \text {-point Likert scale }(0=\text { not true at all } \\
\text { I=rarely true, } 2=\text { sometimes true, } 3=\text { often true, } 4=\text { true nearly al } \\
\text { the time) } \\
\text { - Items scores summed to produce a total score ranging from } 0 \\
64 \text { and subscale scores ranging from } 0-32 \text {, higher scores indicate } \\
\text { better wellbeing }\end{array}$ \\
\hline Social engagement & $\begin{array}{l}\text { - Measured using the number of social contacts and leisure } \\
\text { activities in the preceding } 2 \text { weeks }\end{array}$ & $\begin{array}{l}\text { Questions asked: } \\
\text { - How many times over the last } 2 \text { weeks have you met up with } \\
\text { friends or family? (eg, family or friends visiting, you visiting them } \\
\text { attending a social club) } \\
\text { - How many times over the last } 2 \text { weeks have you participated in } \\
\text { any leisure activities? (eg, hobbies) }\end{array}$ \\
\hline $\begin{array}{l}\text { Global change in } \\
\text { wellbeing and } \\
\text { independence at } 3 \text { and } 6 \\
\text { months }\end{array}$ & $\begin{array}{l}\text { - Participants were asked to provide a rating of their perceived } \\
\text { change using a 5-point ordinal scale. }\end{array}$ & $\begin{array}{l}\text { Questions asked: } \\
\text { - Compared to } 3 / 6 \text { [depending on time since randomization] } \\
\text { months ago when you started in the PRIDE study, how would } \\
\text { you rate your general wellbeing now? Response options: much } \\
\text { better, a bit better, no change, a bit worse, much worse } \\
\text { - Compared to } 3 / 6 \text { [depending on time since randomization] } \\
\text { months ago when you started in the PRIDE study, how inde- } \\
\text { pendent do you feel now? Response options: much more inde- } \\
\text { pendent, a bit more independent, no change, a bit less } \\
\text { independent, much more independent }\end{array}$ \\
\hline & $\begin{array}{l}\text { - Supporters were asked to independently provide a rating of } \\
\text { their perceived change for the person with dementia from their } \\
\text { perspective, during the course of the study, using the same } \\
\text { 5-point ordinal scale }\end{array}$ & $\begin{array}{l}\text { Questions asked: } \\
\text { - Compared to } 3 / 6 \text { months ago [depending on time since rando- } \\
\text { mization] when your friend/relative started in the study, how } \\
\text { would you rate their general wellbeing now? } \\
\text { - Compared to } 3 / 6 \text { months ago [depending on time since rando- } \\
\text { mization] when your friend/relative started in the study, how } \\
\text { independent do you feel they are now? }\end{array}$ \\
\hline \multicolumn{3}{|l|}{ Supporters $^{B}$} \\
\hline $\begin{array}{l}\text { Health-related quality- } \\
\text { of-life }\end{array}$ & $\begin{array}{l}\text { Measured using the EuroQoL Quality-of-Life Questionnaire - } 5 \\
\text { Domains, } 5 \text { Levels } \\
\text { - Consists of two parts: a descriptive system and VAS } \\
\text { - The } 5 \text { level descriptive system used as part of the health } \\
\text { economic analysis and VAS summarized in the quantitative } \\
\text { analysis of the clinical outcomes }\end{array}$ & $\begin{array}{l}\text { - VAS scores range from } 0 \text { (worst health can imagine) to } 100 \text { (best } \\
\text { health can imagine) }\end{array}$ \\
\hline
\end{tabular}

Notes: ${ }^{A}$ For missing data within questionnaires, tool-specific guidance was used to derive scores if available. Otherwise missing items were imputed by the participant mean of the completed responses (rounded to one decimal place) in order to derive scores. ${ }^{24}$ B Mood measured using the General Health Questionnaire was listed as an outcome for supporters in version 1.0 (Sept 18,2018) of the protocol, however this was removed in version 2.0 (Dec 20, 2018) to reduce the burden on participant and supporters in completing questionnaires and was not collected for any supporters. 


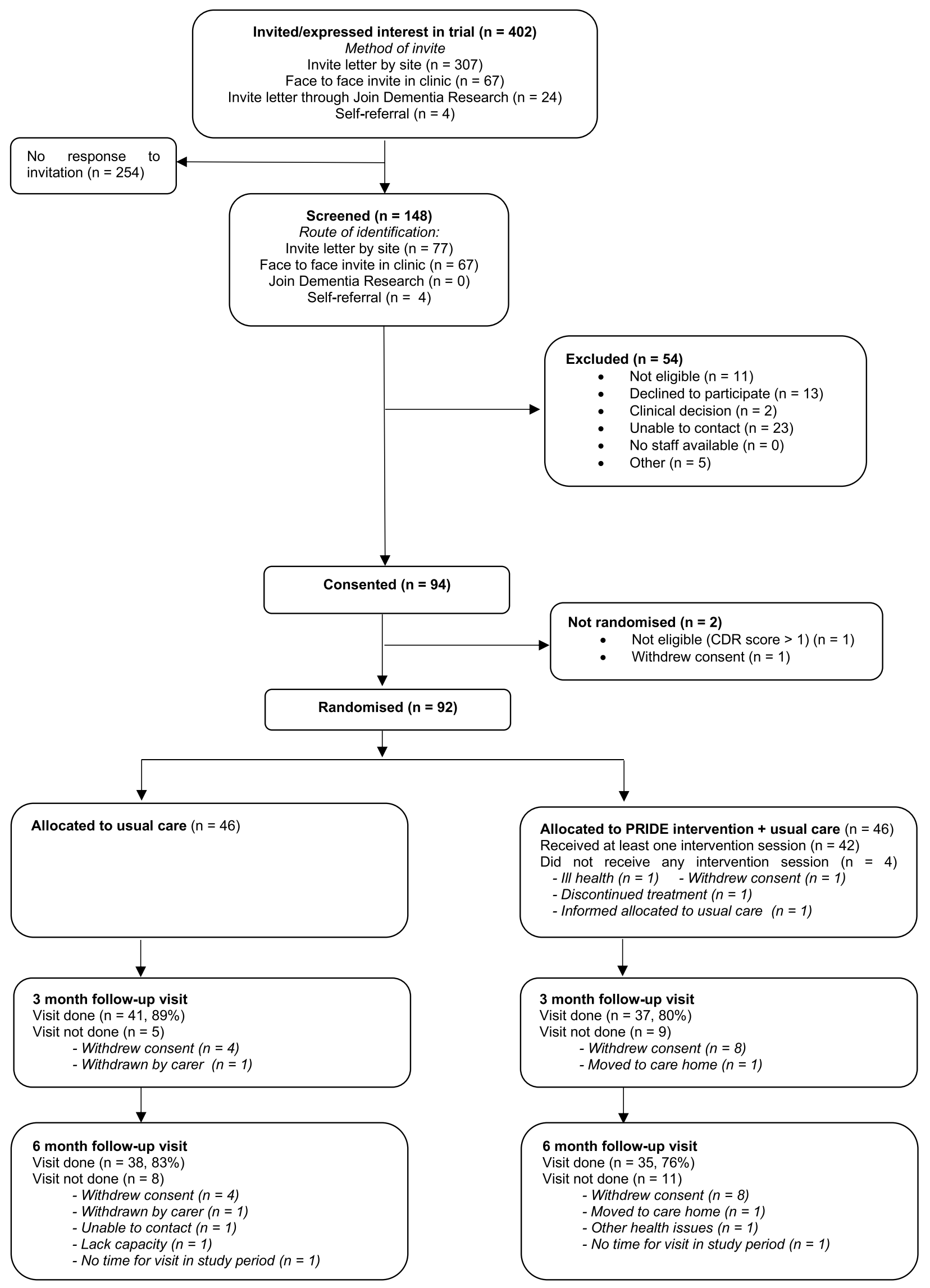

Figure I Participant flow diagram. 
Table 3 Participant Baseline Characteristics Data

\begin{tabular}{|c|c|c|c|}
\hline & $\begin{array}{l}\text { Usual Care } \\
(n=46)\end{array}$ & $\begin{array}{l}\text { PRIDE Intervention } \\
(n=46)\end{array}$ & $\begin{array}{l}\text { Total } \\
(n=92)\end{array}$ \\
\hline \multicolumn{4}{|l|}{ Age at randomization (years) } \\
\hline Mean [SD] & $78.6[7.1]$ & $77.3[8.9]$ & $78.0[8.0]$ \\
\hline Median [25th, 75th centile] & $79[74,85]$ & $78[72,84]$ & $78[73,84]$ \\
\hline Min, $\max$ & 56,90 & 51,93 & 51,93 \\
\hline$\geq 80$ & $21(46 \%)$ & $20(43 \%)$ & $4 \mid(45 \%)$ \\
\hline \multicolumn{4}{|l|}{ Gender } \\
\hline Male & $23(50 \%)$ & $23(50 \%)$ & 46 (50\%) \\
\hline Female & $23(50 \%)$ & $23(50 \%)$ & $46(50 \%)$ \\
\hline \multicolumn{4}{|l|}{ Ethnicity } \\
\hline White & 42 (9l\%) & 44 (96\%) & $86(93 \%)$ \\
\hline Black & I (2\%) & - & I (I\%) \\
\hline Asian & $2(4 \%)$ & $2(4 \%)$ & $4(4 \%)$ \\
\hline Mixed & I (2\%) & - & I (I\%) \\
\hline \multicolumn{4}{|l|}{ Educational attainment } \\
\hline Primary & - & - & - \\
\hline Secondary & $31(67 \%)$ & $26(57 \%)$ & $57(62 \%)$ \\
\hline Higher & $15(33 \%)$ & $19(41 \%)$ & $34(37 \%)$ \\
\hline Not known & - & I (2\%) & $\mathrm{I}(\mathrm{I} \%)$ \\
\hline \multicolumn{4}{|l|}{ Living arrangements } \\
\hline Lives alone & $15(33 \%)$ & $9(20 \%)$ & $24(26 \%)$ \\
\hline Lives with others & $31(67 \%)$ & 37 (80\%) & $68(74 \%)$ \\
\hline \multicolumn{4}{|l|}{ Marital status } \\
\hline Single/divorced/widowed/separated & $16(35 \%)$ & $10(22 \%)$ & $26(28 \%)$ \\
\hline Married/with partner & $30(65 \%)$ & $36(78 \%)$ & $66(72 \%)$ \\
\hline $\begin{array}{l}\text { Facilities available for use of web-based manual (ie, computer and internet } \\
\text { access) }\end{array}$ & $17(37 \%)$ & $16(35 \%)$ & $33(36 \%)$ \\
\hline \multicolumn{4}{|l|}{ Type of dementia } \\
\hline Alzheimer's Type & $31(67 \%)$ & $28(61 \%)$ & $59(64 \%)$ \\
\hline Vascular & $10(22 \%)$ & $9(20 \%)$ & 19 (21\%) \\
\hline Lewy body & - & $2(4 \%)$ & $2(2 \%)$ \\
\hline Mixed & $3(7 \%)$ & $5(11 \%)$ & $8(9 \%)$ \\
\hline Not known & I (2\%) & I (2\%) & $2(2 \%)$ \\
\hline Other (frontotemporal dementia) & I (2\%) & I (2\%) & $2(2 \%)$ \\
\hline Medication taken for dementia ${ }^{\mathrm{A}}$ & $32(70 \%)$ & $32(70 \%)$ & $64(70 \%)$ \\
\hline \multicolumn{4}{|l|}{ Clinical Dementia Rating Scale score } \\
\hline 0.5 (very mild) & $28(6 \mid \%)$ & $35(76 \%)$ & $63(68 \%)$ \\
\hline I (mild) & $18(39 \%)$ & II (24\%) & $29(32 \%)$ \\
\hline Supporter consented to participate & $34(74 \%)$ & $30(65 \%)$ & $64(70 \%)$ \\
\hline Spouse/partner & 23 & 24 & 47 \\
\hline Son/daughter & 9 & 5 & 14 \\
\hline Friend or another relative & 2 & I & 3 \\
\hline
\end{tabular}

Notes: Data are $\mathrm{N}$ (\%) unless otherwise indicated. AMedication for dementia include any of the following: Donepezil Hydrochloride, Rivastigmine, Memantine Hydrochloride, and Galantamine.

was similar in the two groups (Figure 1). Outcome assessment visits were not completed due to withdrawal of consent from the trial and at 6 months due to being unable to organize a visit within the time frame (Figure 1). Participants who did not complete the visit at 6 months were slightly older than those completing the visit 
(mean $=80$ years $[\mathrm{SD}=7]$ vs mean 77 years $[\mathrm{SD}=8]$ ). At the visits, completion of the clinical outcomes was high. All assessments were completed sufficiently to derive a score apart from the standardized mini mental state exam (SMMSE) which was not fully completed by two participants at 3 months and four participants at 6 months, one participant refused to do the PPOM at 6 months and there was insufficient time for completion of the SMMSE and CASP at the 6 month visit for one participant. Between $80 \%$ and $90 \%$ of participants at each time point agreed or strongly agreed that the questions in the EQ-5D and the DEMQoL were relevant to them with between $70 \%$ and $80 \%$ agreeing or strongly agreeing for the other measures. Of the 64 supporters who consented to the trial, 55 (86\%) completed the follow-up questionnaire at 3 months and 52 $(81 \%)$ at 6 months.

At 6 months, $36 \%$ of participants (26/73) rated their wellbeing as a bit better or much better compared to when they started in the study and $22 \%(16 / 73)$ responded that they were a bit more or much more independent (Table 4). Supporters responded that participant wellbeing was a bit/ much better for $13 \%(7 / 52)$ and that the participant was a bit/much more independent for $11 \%(6 / 52)$. The area under the ROC curves (AUC) for improvement in wellbeing using the participant rating at 6 months according to change in baseline in the candidate primary outcomes

Table 4 Wellbeing and Independence: Participant Rating of Change in General Well-Being and Independence at 6 Months Compared to When They Started in the PRIDE Study (Global Change)

\begin{tabular}{|l|l|l|l|}
\hline & $\begin{array}{l}\text { Usual } \\
\text { Care }\end{array}$ & $\begin{array}{l}\text { PRIDE } \\
\text { Intervention }\end{array}$ & Total \\
\hline $\begin{array}{l}\text { Questionnaire completed } \\
\text { at } 6 \text { months }\end{array}$ & 38 & 35 & 73 \\
\hline $\begin{array}{l}\text { General wellbeing } \\
\text { Much worse }\end{array}$ & - & - & \\
A bit worse & $7(18 \%)$ & $6(17 \%)$ & $13(18 \%)$ \\
No change & $18(47 \%)$ & $16(46 \%)$ & $34(47 \%)$ \\
A bit better & $8(21 \%)$ & $8(23 \%)$ & $16(22 \%)$ \\
Much better & $5(13 \%)$ & $5(14 \%)$ & $10(14 \%)$ \\
\hline $\begin{array}{l}\text { Independence } \\
\text { Much less independent }\end{array}$ & $2(5 \%)$ & - & $2(3 \%)$ \\
A bit less independent & $8(21 \%)$ & $5(14 \%)$ & $13(18 \%)$ \\
No change & $20(53 \%)$ & $22(63 \%)$ & $42(58 \%)$ \\
A bit more independent & $6(16 \%)$ & $4(11 \%)$ & $10(14 \%)$ \\
Much more independent & $2(5 \%)$ & $4(11 \%)$ & $6(8 \%)$ \\
\hline
\end{tabular}

Note: Percentages use the number of participants completing the questionnaire at 6 months as the denominator. ranged from $0.55-0.74$ (Table 5) with the greatest area observed for the CASP12. Similar values were observed for the AUC using the participant rating of independence as the external criterion for improvement. The AUC for no decline in independence using the global change question was also evaluated in a post hoc analysis with change in CASP12 having the greatest AUC for no decline (0.65, 95\% CI $=0.48-0.83$ ). All estimates of the minimal important change for the candidate primary outcome measures shown in Table 6 have wide confidence intervals, although estimates in general were fairly similar using either the participant or supporter rating of change for each estimation method.

Scores on the clinical outcomes were similar in the two groups at all time points (Table 7). In Figure 2, 95\% confidence intervals for the difference between groups include 0 for all of the candidate primary outcome measures. The $85 \%$ and $75 \%$ CIs are supportive of small differences favoring the intervention group for the IADL, however in contrast for the CASP $85 \%$ and $75 \% \mathrm{CIs}$ mostly lie below 0 (ie, favoring the usual care group) with upper limits between 0 and 1 .

\section{Discussion}

This feasibility trial demonstrated that it is possible to conduct a definitive multi-center randomized controlled trial of the PRIDE intervention for people with dementia. A key strength of the study was our ability to recruit participants across varied sites in terms of local dementia service provision. With the exception of one site who adopted a wide net approach to screening, the retention rate from screening through to randomization was high, indicating that the screening procedures worked well and wide net approaches to recruitment are not efficient in terms of delivery of a trial such as ours. From a variety of recruitment methods, face to face invitations via the clinic or letters sent by the clinical sites were most successful. There was a high attendance rate for those receiving the intervention with non-attendance due to participants withdrawing from the trial, possibly due to losing momentum as sessions were spaced over 2 months. Across the sites we were able to train an adequate number of staff to act as facilitators, and local NHS Clinical Research Networks - CRNs - were very helpful and effective in sourcing research staff to recruit and collect data for this study.

Recruitment of study sites and participants is the key to the success of any trial. ${ }^{27}$ Following our field testing prior 
Table 5 Responsiveness to Change at 6 Months for Candidate Primary Outcome Measures

\begin{tabular}{|c|c|c|c|c|c|c|c|c|}
\hline & \multicolumn{2}{|l|}{ IADL } & \multicolumn{2}{|l|}{ DEMQOL } & \multicolumn{2}{|l|}{ CASPI9 } & \multicolumn{2}{|l|}{ CASPI 2} \\
\hline & $\begin{array}{l}\text { Participant } \\
(n=73)\end{array}$ & $\begin{array}{l}\text { Supporter } \\
(n=52)\end{array}$ & $\begin{array}{l}\text { Participant } \\
(n=73)\end{array}$ & $\begin{array}{l}\text { Supporter } \\
(n=52)\end{array}$ & $\begin{array}{l}\text { Participant } \\
(n=72)\end{array}$ & $\begin{array}{l}\text { Supporter } \\
(n=52)\end{array}$ & $\begin{array}{l}\text { Participant } \\
(n=72)\end{array}$ & $\begin{array}{l}\text { Supporter } \\
(n=52)\end{array}$ \\
\hline Well-being & & & & & & & & \\
\hline $\begin{array}{l}\text { Spearman correlation between change } \\
\text { from baseline at } 6 \text { months and global } \\
\text { change in wellbeing question }\end{array}$ & 0.19 & 0.26 & 0.08 & 0.22 & 0.34 & 0.33 & 0.40 & 0.24 \\
\hline $\begin{array}{l}\text { Area under the ROC curve for improvers } \\
\text { in wellbeing according to change from } \\
\text { baseline at } 6 \text { months }(95 \% \mathrm{Cl})\end{array}$ & $\begin{array}{l}0.61(0.48- \\
0.74)\end{array}$ & $\begin{array}{l}0.59(0.36- \\
0.83)\end{array}$ & $\begin{array}{l}0.55(0.41- \\
0.69)\end{array}$ & $\begin{array}{l}0.73(0.53- \\
0.94)\end{array}$ & $\begin{array}{l}0.71(0.59- \\
0.83)\end{array}$ & $\begin{array}{l}0.66(0.45- \\
0.87)\end{array}$ & $\begin{array}{l}0.74(0.62- \\
0.85)\end{array}$ & $\begin{array}{l}0.59(0.37- \\
0.81)\end{array}$ \\
\hline Independence & & & & & & & & \\
\hline $\begin{array}{l}\text { Spearman correlation between change } \\
\text { from baseline at } 6 \text { months and global } \\
\text { change in independence question }\end{array}$ & 0.17 & 0.09 & -0.08 & 0.29 & 0.29 & 0.49 & 0.34 & 0.41 \\
\hline $\begin{array}{l}\text { Area under the ROC curve for improvers } \\
\text { in independence according to change } \\
\text { from baseline at } 6 \text { months }(95 \% \mathrm{Cl})\end{array}$ & $\begin{array}{l}0.67(0.50- \\
0.84)\end{array}$ & $\begin{array}{l}0.54(0.29- \\
0.79)\end{array}$ & $\begin{array}{l}0.45(0.28- \\
0.61)\end{array}$ & $\begin{array}{l}0.68(0.42- \\
0.95)\end{array}$ & $\begin{array}{l}0.70(0.57- \\
0.83)\end{array}$ & $\begin{array}{l}0.72(0.52- \\
0.93)\end{array}$ & $\begin{array}{l}0.73(0.60- \\
0.85)\end{array}$ & $\begin{array}{l}0.74(0.50- \\
0.97)\end{array}$ \\
\hline
\end{tabular}

to this feasibility trial, we concluded that stringent site selection is important. ${ }^{10}$ Being clear on what is expected of the trial sites themselves enabled recruitment to be carried out more smoothly compared with our previous study. ${ }^{3}$ Requiring the sites to identify their own intervention facilitators was also a successful strategy. This was because in-house organization meant that time and resources could be better managed by the team themselves, who also had control over ensuring adequate staff were in place throughout the trial. This is vital in a trial that is resource heavy both at sites and within the research team, and the time required to keep the study on track due to the variability of services. Even with each site requiring to meet the same criteria, there were differences in site configuration and individual approaches, but this demonstrates a larger trial would be feasible even with variation. Maintaining good communication between the research team and the sites was required, especially for those with less research experience.

There was a high completion rate for all the outcome measures indicating that they were feasible to use in both arms of the study, and that the overall time taken and number of measures included was reasonable. Comparing the responsiveness to change of the candidate primary outcome measures in terms of wellbeing and independence, the CASP12 appeared to perform slightly better than the other options including the CASP 19, the IADL, and the DemQol. Further work is needed to estimate the minimal important change for these outcome measures as, due to the sample size in this study, confidence intervals for the estimates were wide. Preliminary evidence of the effectiveness of the intervention using these three outcome measures was, however, conflicting and did not signal an effect of the intervention on the CASP measure. Interpretation of this data should be treated with caution since this was not the main aim of this feasibility study. Taking into account the performance of the measures, a future trial could substitute the DemQol and the CASP19 for related shorter instruments such as the CASP-12 and other relevant measures arising from recent reviews on outcome measures for studies of this type. ${ }^{27,28}$

Given that people with dementia think that "in the moment" measurement is perhaps more reflective of their response to psychosocial interventions, ${ }^{29}$ there is scope to incorporate emerging digital Experience Sampling Methods $(\mathrm{ESM})^{30}$ in a future definitive RCT of the PRIDE intervention.

The PRIDE intervention appears to be a useful and relevant way to try to improve independence and a range of activities for people with early stages of dementia. However, although it was popular and easy to use, at this stage we do not have a clear idea of the potential clinical benefits in practice. Based on this feasibility trial, we are now able to design a full scale protocol for a large multicenter trial of the PRIDE intervention compared to usual care, with some alterations and reductions to the range of outcome measures we examined. 
Table 6 Estimates of the Minimal Important Change (MIC) at 6 Months for the Candidate Primary Outcomes Measures

\begin{tabular}{|c|c|c|}
\hline & $\begin{array}{l}\text { Using Participant Response to Global } \\
\text { Change Question } \\
\text { MIC Estimate }(95 \% \mathrm{CI})\end{array}$ & $\begin{array}{l}\text { Using Supporter Response to Global } \\
\text { Change Question } \\
\text { MIC Estimate }(95 \% \mathrm{Cl})\end{array}$ \\
\hline \multicolumn{3}{|c|}{ Using global change in well-being as anchor } \\
\hline \multicolumn{3}{|l|}{ IADL } \\
\hline Between patient score change & $0.2(-0.6$ to 1.0$)$ & $-0.2(-1.6$ to I.I) \\
\hline Sensitivity/specificity approach & $0.4(-2$ to 2$)$ & $0(-2$ to 2$)$ \\
\hline \multicolumn{3}{|l|}{ DEMQoL $^{\mathrm{A}}$} \\
\hline Between patient score change & $3.6(-3.1$ to 10.3$)$ & $4.6(-6.7$ to 15.8$)$ \\
\hline Sensitivity/specificity approach & $5(-7$ to 18$)$ & $12(0$ to 14$)$ \\
\hline \multicolumn{3}{|l|}{ CASPI9 } \\
\hline Between patient score change & $3.5(0.1$ to 6.9$)$ & $3.7(-4.5$ to $\mid \mathrm{I} .8)$ \\
\hline Sensitivity/specificity approach & $-3(-3$ to 3$)$ & I $(-3$ to 7$)$ \\
\hline \multicolumn{3}{|l|}{ CASPI2 } \\
\hline Between patient score change & $2.3(-0.1$ to 4.7$)$ & $2(-4$ to 7.9$)$ \\
\hline Sensitivity/specificity approach & I $(-3$ to 3$)$ & $-3(-3$ to 5$)$ \\
\hline \multicolumn{3}{|c|}{ Using global change in independence as anchor } \\
\hline \multicolumn{3}{|l|}{ IADL } \\
\hline Between patient score change & $0.6(-0.4$ to 1.6$)$ & $-0.6(-2$ to 0.8$)$ \\
\hline Sensitivity/specificity approach & $0.4(-1$ to 2$)$ & $0(-2$ to 2$)$ \\
\hline \multicolumn{3}{|l|}{ DEMQoL $^{\mathrm{A}}$} \\
\hline Between patient score change & Not calculated ${ }^{A}$ & $1.7(-8.7$ to 12.1$)$ \\
\hline Sensitivity/specificity approach & & $6(-4$ to 18$)$ \\
\hline \multicolumn{3}{|l|}{ CASPI9 } \\
\hline Between patient score change & $2.6(-1.7$ to 6.8$)$ & $2.6(-3.8$ to 8.9$)$ \\
\hline Sensitivity/specificity approach & $0(-1$ to 2$)$ & I $(-2$ to 8$)$ \\
\hline \multicolumn{3}{|l|}{ CASPI2 } \\
\hline Between patient score change & $1.6(-1.4$ to 4.7$)$ & $1.3(-3.1$ to 5.7$)$ \\
\hline Sensitivity/specificity approach & $0(-1$ to 3$)$ & $4(-3$ to 5$)$ \\
\hline
\end{tabular}

Notes: ${ }^{A}$ MIC not calculated for the DEMQoL using the participant rating of independence at 6 months: For the between patient score change approach as the mean change in DEMQoL score for participants rating themselves as a bit more independent was less than the mean change in the group rating themselves as having no change in independence. For the sensitivity/specificity approach as Table 5 shows that discriminatory ability of DEMQoL to discriminate between improvers and non-improvers is less than chance (area under curve <0.5). Between patient score change: MIC calculated as the difference between the mean change in the group with a response of a bit better/a bit more independent and the group with a response of no change on the global change questions. Sensitivity/specificity approach: MIC defined as the change from baseline that maximizes the Youden Index (sensitivity + specificity - I) to discriminate between improvers and non-improvers. Confidence intervals for sensitivity/specificity approach estimated using bootstrapping with I,000 repetitions. IADL scores range from 0 (low function) to 8 (high function). DEMQoL scores range from 28- II2, higher scores indicating better quality-of-life. CASP scores for 19 item version range from $0-57$ and for 12 item version range from 0-36, with higher scores indicating better quality-of-life. Abbreviations: IADL, Lawton Instrumental Activities of Daily Living Score; CASP, Control, Autonomy, Self-realization, and Pleasure Scale.

It should be acknowledged, however, that the COVID-19 pandemic is likely to have a continued impact on care delivered in the community for people with dementia, but may also add limitations to what people are able to do in terms of activities outside the house. We suggest that the PRIDE intervention can be delivered with minimal contact in the home and is flexible in its tailoring to individual needs, preferences, and circumstances to be further tailored to individuals affected by the changes imposed through the current COVID-19 epidemic. Although only one participant used the online version, since the recent COVID-19 epidemic and its strategies for safety, many people have resorted to online resources in communication and gaining knowledge. Ongoing work from our research team on a refined PRIDE webbased solution will allow for tailoring of the PRIDE interventions including for those who have become further isolated and fearful during and beyond the epidemic. 
Table 7 Participant Clinical Outcomes Summary by Allocated Group

\begin{tabular}{|c|c|c|c|}
\hline & Baseline Mean [SD] & 3 Months Mean [SD] & 6 Months Mean [SD] \\
\hline \multicolumn{4}{|l|}{ Lawton Instrumental Activities of Daily Living total score } \\
\hline Usual care & $5.6[1.5](n=46)$ & $5.2[1.7](n=41)$ & $4.7[1.7](n=38)$ \\
\hline PRIDE intervention & $5.0[1.7](n=46)$ & $4.6[2.1](n=37)$ & $4.8[2.1](n=35)$ \\
\hline \multicolumn{4}{|l|}{ EQ-5D-5L health status VAS score } \\
\hline Usual care & $73.0[19.5](n=45)$ & $73.8[15.6](n=41)$ & $75.1[17.4](n=38)$ \\
\hline PRIDE intervention & $70.5[17.2](n=46)$ & $68.4[18.7](n=37)$ & $67.4[17.9](n=34)$ \\
\hline \multicolumn{4}{|l|}{ DEMQoL total score } \\
\hline Usual care & $88.0[14.3](n=46)$ & $90.3[14.1](n=41)$ & $91.0[15.0](n=38)$ \\
\hline PRIDE intervention & $87.8[13.5](n=46)$ & $90.1[13.7](n=37)$ & $89.5[12.7](n=35)$ \\
\hline \multicolumn{4}{|l|}{ Geriatric Depression Scale total score } \\
\hline Usual care & $3.8[3.5](n=46)$ & $3.4[3.1](n=4 I)$ & $3.4[3.0](n=38)$ \\
\hline PRIDE intervention & $4.6[3.5](n=46)$ & $4.1[2.8](n=37)$ & $3.8[3.3](n=35)$ \\
\hline \multicolumn{4}{|l|}{ Standardized Mini Mental State Exam total score } \\
\hline Usual care & $23.6[3.6](n=45)$ & $23.7[3.2](n=40)$ & $23.4[3.9](n=35)$ \\
\hline PRIDE intervention & $24.3[4.0](n=46)$ & $24.4[3.4](n=36)$ & $24.2[4.3](n=33)$ \\
\hline \multicolumn{4}{|l|}{ Control, Autonomy, Self-realization, and Pleasure Scale (CASP-19) } \\
\hline Usual care & $41.3[8.6](n=46)$ & $42.0[8.3](n=4 I)$ & $42.5[8.8](n=37)$ \\
\hline PRIDE intervention & $39.1[9.7](n=46)$ & $40.7[8.9](n=37)$ & $39.4[10.1](n=35)$ \\
\hline \multicolumn{4}{|l|}{ CASP-12 } \\
\hline Usual care & $25.8[5.8](n=46)$ & $26.5[6.0](n=4 I)$ & $26.7[6.1](n=37)$ \\
\hline PRIDE intervention & $24.6[6.7](n=46)$ & $25.8[6.0](n=37)$ & $24.6[7.0](n=35)$ \\
\hline \multicolumn{4}{|l|}{ Impact on Participation and Autonomy (IPAQ-O) - Social Relations Sub-Scale ${ }^{\mathrm{A}}$} \\
\hline Usual care & $9.4[2.9](n=46)$ & $9.6[2.4](n=4 I)$ & $8.8[2.4](n=38)$ \\
\hline PRIDE intervention & $9.2[3.2](n=46)$ & $8.7[2.6](n=37)$ & $8.5[2.7](n=35)$ \\
\hline \multicolumn{4}{|l|}{ Positive Psychology Outcome Measure (PPOM) } \\
\hline \multicolumn{4}{|l|}{ Total } \\
\hline Usual care & $47.9[9.8](n=46)$ & $47.5[9.6](n=4 I)$ & $47.4[10.4](n=38)$ \\
\hline PRIDE intervention & $46.6[10.8](=46)$ & $46.3[10.3](n=37)$ & $47.6[7.8](n=34)$ \\
\hline \multicolumn{4}{|l|}{ Hope } \\
\hline Usual care & $24.4[5.1](n=46)$ & $24.9[4.8](n=41)$ & $24.3[5.3](n=38)$ \\
\hline PRIDE intervention & $24.3[5.5](n=46)$ & $23.8[5.7](n=37)$ & $24.3[3.9](n=34)$ \\
\hline \multicolumn{4}{|l|}{ Resilience } \\
\hline Usual care & $23.5[5.4](n=46)$ & $22.7[5.6](n=41)$ & $23.1[5.8](n=38)$ \\
\hline PRIDE intervention & $22.3[6.0](n=46)$ & $22.5[5.3](n=37)$ & $23.2[5.5](n=34)$ \\
\hline \multicolumn{4}{|l|}{ Social engagement } \\
\hline \multicolumn{4}{|l|}{ Number of times in the last 12 weeks met up with friends or family } \\
\hline Usual care & $6.9[5.8](n=46)$ & $7.7[5.2](n=40)$ & $7.4[4.6](n=38)$ \\
\hline PRIDE intervention & $6.3[4.6](n=46)$ & $8.3[6.1](n=37)$ & $8.1[6.7](n=35)$ \\
\hline \multicolumn{4}{|l|}{ Number of times over the last 12 weeks participated in any leisure activities } \\
\hline Usual care & $5.5[5.2](n=45)$ & $6.7[5.4](n=4 I)$ & $4.6[4.4](n=38)$ \\
\hline PRIDE intervention & $8.7[12.0](n=46)$ & $8.6[6.9](n=36)$ & $7.2[7.0](n=34)$ \\
\hline
\end{tabular}

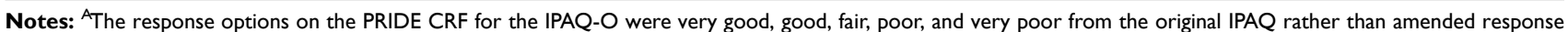
options for the IPAQ-O (totally agree, partly agree, neither agree nor disagree, disagree, and totally disagree). Items scored as on the original IPAQ to derive the IPAQ-O social relations score. IADL scores range from 0 (low function) to 8 (high function). EQ-5D-5L VAS scores range from 0 (worst health can imagine) to I00 (best health can imagine). DEMQoL scores range from 28-112, higher scores indicating better quality-of-life. GDS scores ranging from 0-15, with higher scores indicating more severe depression. sMMSE scores range from 0-30, with a lower score indicating more cognitive impairment. CASP: for 19 item version scores range from 0-57 and for 12 item version scores range from 0-36, with higher scores indicating better quality-of-life. IPAQ-O social relations subscale scores range from 5-25, with higher score indicating more restriction in participation. PPOM total scores range from 0-64 and subscale scores range from 0-32, higher scores indicate better wellbeing. 
A IADL
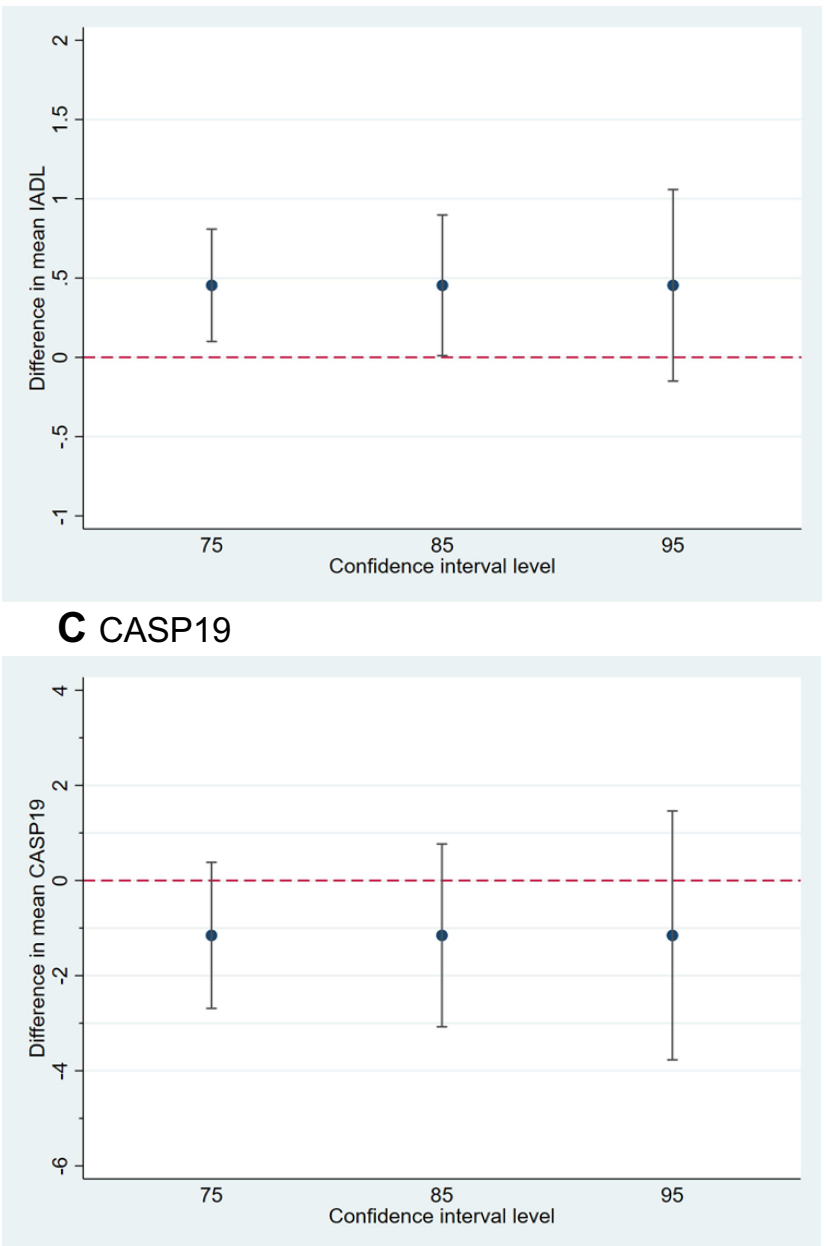

B DEMQoL

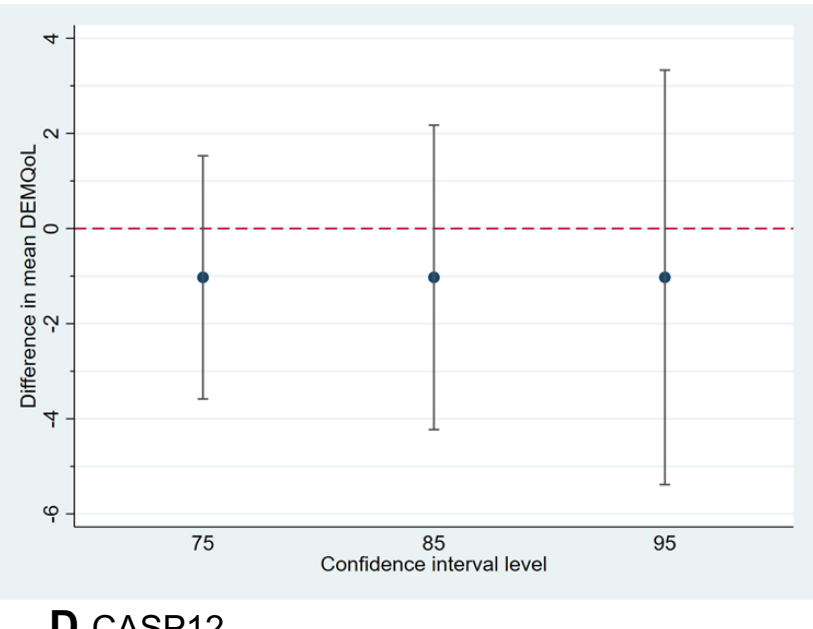

D CASP12

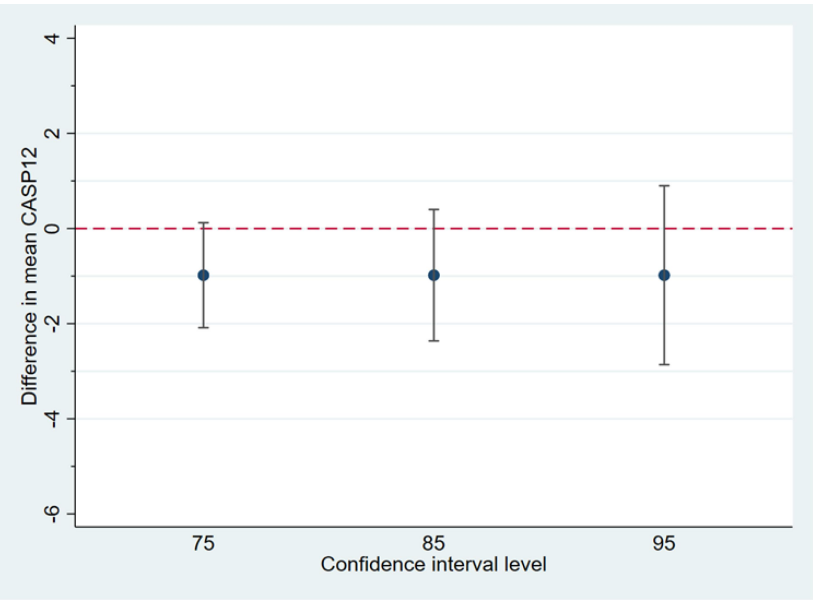

Figure 2 Difference in means (intervention - control) at 6 months with confidence intervals for the candidate primary outcomes.

Notes: Positive values indicate improvement for all outcomes. (A) Difference in mean Instrumental Activities of Daily Living at 6 months. (B) Difference in mean DEMQoL (quality-of-life) at 6 months. (C) Difference in mean Control, Autonomy, Self-realization, and Pleasure scale 19 item version at 6 months. (D) Difference in mean Control, Autonomy, Self-realization, and Pleasure scale 12 item version at 6 months.

\section{Conclusion}

This study demonstrated that it is feasible to recruit to and carry out a multi-center trial of an individually tailored manualized PRIDE intervention in community-dwelling people who have mild dementia. The intervention was well received with a high completion rate and the outcome measures were completed to a high standard. Although measurable clinical benefit of the PRIDE intervention is not clear at present, a future large scale RCT has the potential to provide evidence of clinical and cost effectiveness. PRIDE is a relatively lowresourced 3-session intervention that is easy to deliver, and has scope to be scaled up across the health and social care services. The PRIDE web-application for tailoring towards those who have become seriously isolated during the current COVID-19 epidemic is an avenue for future study.

\section{Data Sharing Statement}

The datasets generated during and/or analyzed during the current study will be available upon reasonable request from Nottingham Clinical Trials Unit.

Email: ctu@nottingham.ac.uk Telephone: +44 (0)115 8231600 .

\section{Ethical Approval}

The study was approved by West Midlands - Solihull Research Ethics Committee (REC) (Ref: 18/WM/0281). Trial Registration: ISRCTN: 11288961.

\section{Acknowledgments}

We would like to acknowledge and thank the sponsor, The University of Nottingham, and the research sites and 
participants The authors would also like to thank the larger Pride team for their input: Holly Walton, Aimee Spector, Susan Michie, Eef Hogervorst, Linda Birt, Fiona Poland, Paul Higgs, Ula Htay, David Prothero, Thomas Stevens, Monica Panca, Jem Bhatt, Ruth Hacket, Hilary Davies, Snorri Rafnsson, and Reuben Ogollah, Lucy Bradshaw, and Samantha Beard at the Nottingham Clinical Trials Unit. Members of the independent Trial Steering Committee: Myrra Vernooij-Dassen, Yun-Hee Jeon, Bob Woods, and Rabih Chattat.

\section{Author Contributions}

All authors made substantial contributions to the conception and design, acquisition of data, or analysis and interpretation of data; took part in drafting the article or revising it critically for important intellectual content; agreed to submit to the current journal; gave final approval of the version to be published; and agree to be accountable for all aspects of the work.

\section{Funding}

This work was supported by the Economic and Social Research Council/National Institute of Health [grant number ES/L001802/2]. This article presents independent research funded by the National Institute for Health Research (NIHR). The views expressed are those of the authors and not necessarily those of the NHS, the NIHR or the Department of Health.

\section{Disclosure}

Kirsty Sprange reports a grantfrom National Institute of Health Research (NIHR), during the conduct of the study. Martin Orrell reports grants from NIHR/ESRC, during the conduct of the study. The authors report no other potential conflicts of interest for this work.

\section{References}

1. Sterin J. Essay on a word: a lived experience of Alzheimer's disease. Dementia. 2002;1(1):7-10. doi:10.1177/147130120200100103

2. Department of Health. Prime minister's challenge on dementia 2020: implementation plan; 2016. Available from: https://www.gov.uk/gov ernment/uploads/system/uploads/attachment_data/file/507981/PM_ Dementia-main_acc.pdf. Accessed February 25, 2019.

3. Csipke E, Yates L, Moniz-Cook E, et al. Promoting independence in dementia (PRIDE): protocol for a feasibility trial of the PRIDE intervention for living well with mild dementia. Int J Clin Trials. 2018;5 (4):177-185. doi:10.18203/2349-3259.ijct20184399

4. Yates L, Csipke E, Moniz-Cook E, et al. The development of the promoting independence in dementia (PRIDE) intervention to enhance independence in dementia. Clin Interv Aging. 2019;14:1615-1630.

5. Toms GR, Quinn C, Anderson DE, Clare L. Help yourself: perspectives on self-management from people with dementia and their caregivers. Qual Health Res. 2015;25(1):87-98. doi:10.1177/ 1049732314549604
6. Mountain GA, Craig CL. What should be in a self-management programme for people with early dementia? Aging Ment Health. 2012;16(5):576-583. doi:10.1080/13607863.2011.651430

7. Bodenheimer T, Lorig K, Holman H, Grumbach K. Patient self-management of chronic disease in primary care. JAMA. 2002;288(19):2469-2475. doi:10.1001/jama.288.19.2469

8. Lorig KR, Holman R. Self-management education: history, definition, outcomes, and mechanisms. Ann Behav Med. 2003;26(1):1-7. doi:10.1207/S15324796ABM2601_01

9. McDermott O, Charlesworth G, Hogervorst E, et al. Psychosocial interventions for people with dementia: a synthesis of systematic reviews. Aging Ment Health. 2018;1-11.

10. Csipke E, Moniz-Cook E, Lueng P, et al. Feasibility and acceptability evaluation of the PRIDE (promoting independence in dementia) intervention for living well with dementia. Int Psychogeriatr. 2020.

11. Shafayat A, Csipke E, Bradshaw L, et al. Promoting independence in dementia (PRIDE): protocol for a feasibility randomized controlled trial. Trials. 2019;20(1):709. doi:10.1186/s13063-019-3838-x

12. Morris JC. The clinical dementia rating (CDR): current version and scoring rules. Neurology. 1993;43(11):2412-2414. doi:10.1212/ WNL.43.11.2412-a

13. Moniz-Cook E, Vernooij-Dassen M, Woods R. A European consensus on outcome measures for psychosocial intervention research in dementia care. Aging Ment Health. 2008;12(1):14-29. doi:10.1080/ 13607860801919850

14. Dementia outcome measures: Charting new territory. JPND research. Available from: https://www.neurodegenerationresearch.eu/wpcontent/uploads/2015/10/JPND-Report-Fountain.pdf. Accessed October 20, 2020.

15. Lawton MP, Brody EM. Assessment of older people: self-maintaining and instrumental activities of daily living. Gerontologist. 1969;9(3 Part 1):179-186. doi:10.1093/geront/9.3_Part_1.179

16. Smith SC, Lamping DL, Banerjee S. Measurement of health-related quality of life for people with dementia: development of a new instrument (DEMQOL) and an evaluation of current methodology. Health Technol Assess. 2005;9(10):1-112. doi:10.3310/hta9100

17. EuroQoL Group. EuroQoL: a new facility for the measurement of health related quality of life. Health Policy (New York). 1990;16 (3):199-208. doi:10.1016/0168-8510(90)90421-9.

18. Yesavage JA. Geriatric depression scale. Psychopharmacol Bull. 1988;24:4.

19. Vertesi A, Lever JA, Molloy DW, et al. Standardized mini-mental state examination. Use and interpretation. Can Fam Physician. 2001;47:2018-2023.

20. Hyde M, Wiggins RD, Higgs P, et al. Measure of quality of life in early old age: the theory, development, and properties of a needs satisfaction model (CASP-19). Aging Ment Health. 2003;7186-194. doi:10.1080/1360786031000101157

21. Hammar IO, Ekelund C, Wilhelmson K, et al. Impact on participation and autonomy: test of validity and reliability for older persons. $J$ Health Psychol. 2014;2(3):1825. doi:10.4081/ hpr.2014.1825

22. Stoner CR, Orrell M, Long M, et al. The development and preliminary psychometric properties of two positive psychology outcome measures for people with dementia: the PPOM and the EID-Q. BMC Geriatr. 2017;17(1):72. doi:10.1186/s12877-017-0468-6

23. Cardol M, de Haan RJ, de Jong BA, et al. Psychometric properties of the impact on participation and autonomy questionnaire. Arch Phys Med Rehabil. 2001;82(2):210-216. doi:10.1053/ apmr.2001.18218

24. Bell ML, Fairclough DL, Fiero MH, et al. Handling missing items in the hospital anxiety and depression scale (HADS): a simulation study. BMC Res Notes. 2006;9(1):479. doi:10.1186/s13104-016-2284-z

25. Mokkink LC, Terwee D, Patrick J, et al. COSMIN checklist manual. Amsterdam VU university medical centre 2012. Qual Life Res. 2010;19(4):539-549. doi:10.1007/s11136-010-9606-8 
26. Lee EC, Whitehead AL, Jacques RM, et al. The statistical interpretation of pilot trials: should significance thresholds be reconsidered? BMC Med Res Methodol. 2004;14(1):41. doi:10.1186/1471-2288-14-41

27. Watson JL, Ryan L, Silverberg N, Cahan V, Bernard MA. Obstacles and opportunities in Alzheimer's clinical trials recruitment. Health Aff. 2014;33(4):574-579. doi:10.1377/hlthaff.2013.1314

28. Clarke C, Woods B, Moniz-Cook E, et al. Measuring the wellbeing of people with dementia: a conceptual scoping review. Health Qual Life Outcomes. 2020;18(1):249. doi:10.1186/s12955-020-01440-x

29. Harding A, Morbey H, Ahmed F, Opdebeeck C. A core outcome set of core non-pharmacological community based interventions for people living with dementia at home: a systematic review of outcome measurement instruments. Geront. 2020. doi:10.1093/geront/gnaa071

30. Øksnebjerg L, Diaz-Ponce A, Gove D, et al. Towards capturing meaningful outcomes for people with dementia in psychosocial intervention research: a pan-European consultation. Health Expect. 2018;21(6):1056-1065. doi:10.1111/hex.12799
31. Bartels SL, van Knippenberg RJM, Malinowsky C, Verhey FRJ, de Vugt ME. Smartphone-based experience sampling in people with mild cognitive impairment: feasibility and usability study. JMIR Aging. 2020;3(2):e19852. doi:10.2196/19852

32. Copay A, Subach B, Glassman S, et al. Understanding the minimum clinically important difference: a review of concepts and methods. Spine J. 2007;7(5):541-546. doi:10.1016/j.spinee.2007.01.008

33. Perkins N, Schistermann E. The inconsistency of "optimal" cutpoints obtained using two criteria based on the receiver operating characteristic curve. Am J Epidemiol. 2006;163(7):670-675. doi:10.1093/aje/kwj063

\section{Publish your work in this journal}

Clinical Interventions in Aging is an international, peer-reviewed journal focusing on evidence-based reports on the value or lack thereof of treatments intended to prevent or delay the onset of maladaptive correlates of aging in human beings. This journal is indexed on PubMed Central, MedLine, CAS, Scopus and the Elsevier
Bibliographic databases. The manuscript management system is completely online and includes a very quick and fair peer-review system, which is all easy to use. Visit http://www.dovepress.com/ testimonials.php to read real quotes from published authors. 